GARCEZ, B.S. et al. Determinação dos parâmetros fermentativos de leguminosas pela técnica in vitro semi-automática de produção de gases. PUBVET, Londrina, V. 8, N. 5, Ed. 254, Art. 1683, Março, 2014.

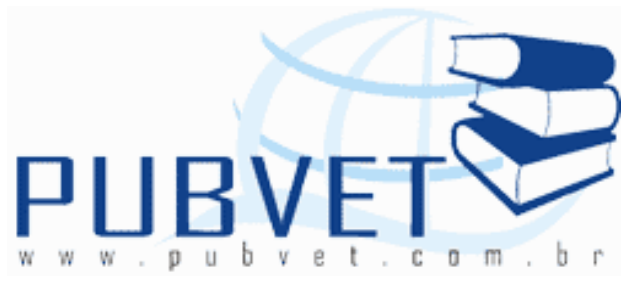

PUBVET, Publicações em Medicina Veterinária e Zootecnia.

\title{
Determinação dos parâmetros fermentativos de leguminosas pela técnica in vitro semi-automática de produção de gases ${ }^{1}$
}

\section{Bruno Spíndola Garcez², Cauê Soares Câmara², Miguel Arcanjo Moreira Filho², Vânia Rodrigues Vasconcelos² e Márcia Mourão Ramos Azevedo²}

1 Trabalho de conclusão de curso do primeiro Autor/Centro de Ciências Agrárias/Universidade Federal do Piauí (UFPI), sob orientação da Professora Vânia Rodrigues Vasconcelos.

2 Programa de Pós Graduação em Ciência Animal/CCA/UFPI

\section{Resumo}

Avaliou-se a composição bromatológica e a dinâmica de fermentação ruminal dos carboidratos totais (CT) de vagens de bordão-de-velho e angico-branco pela técnica in vitro semi-automática de produção de gases. Foram determinados os teores de matéria seca (MS), matéria mineral (MM), proteína bruta (PB), fibra em detergente neutro (FDN), fibra em detergente ácido (FDA), extrato etéreo (EE), carboidratos totais (CHOT) e carboidratos não fibrosos (CNF). As leituras de pressão foram realizadas às $3,5,7,9,12,16$, $20,24,28,34,46,59$ e $72 \mathrm{~h}$. Os maiores volumes de gases foram verificados no bordão-de-velho, enquanto o angico apresentou menor capacidade de fermentação produzindo menos volume de gases. $O$ bordão-de-velho apresentou maior taxa de produção de gases $(c)$, diferindo $(P<0,05)$ do 
GARCEZ, B.S. et al. Determinação dos parâmetros fermentativos de leguminosas pela técnica in vitro semi-automática de produção de gases. PUBVET, Londrina, V. 8, N. 5, Ed. 254, Art. 1683, Março, 2014.

angico. Quanto à eficiência microbiana $(A)$, houve diferença $(P<0,05)$ entre as forrageiras, com maior valor para o bordão-de-velho. O bordão-de-velho e o angico apresentaram potencial para uso na alimentação de ruminantes por serem de boa qualidade do ponto de vista fermentativo. O bordão de velho apresenta melhores parâmetros fermentativos, o que pode ser atribuído ao maior teor de carboidratos não fibrosos, em comparação com o angico branco.

Palavras-chave: Carboidratos totais, fermentação, Samanea saman

\title{
Determination of fermentative parameters of legumes for in vitro technique semi-automatic gas production ${ }^{1}$
}

\begin{abstract}
We evaluated the chemical composition and dynamics of ruminal fermentation of carbohydrate (CT) of pods bourdon old and white angico by in vitro semiautomatic gas production. The contents of dry matter (DM), mineral matter $(M M)$, crude protein $(C P)$, neutral detergent fiber (NDF), acid detergent fiber (ADF), ether extract (EE), total carbohydrates (TC) and non-fiber carbohydrates (NFC). Pressure readings were taken at 3, 5, 7, 9, 12, 16, 20, $24,28,34,46,59$ and $72 \mathrm{~h}$. The largest volumes of gas were observed in the bourdon old, end white angico showed less fermentation capacity producing less gas volume. The bourdon old had higher rates of gas production (c), differing $(P<0.05)$ of the angico. Regarding microbial efficiency $(A)$, significant differences $(P<0.05)$ among the forages, with greater value for the rod-moss. The bourdon old and angico showed potential for use in ruminant feed because they are good quality standpoint fermentation. The bourdon old shows better fermentative parameters, which can be attributed to the higher content of nonfiber carbohydrates, compared with white angico.
\end{abstract}

Keywords: Total Carbohydrates, fermentation, Samanea saman 
GARCEZ, B.S. et al. Determinação dos parâmetros fermentativos de leguminosas pela técnica in vitro semi-automática de produção de gases. PUBVET, Londrina, V. 8, N. 5, Ed. 254, Art. 1683, Março, 2014.

\section{INTRODUÇÃO}

Os custos com alimentação dos rebanhos representam cerca de $60 \%$ das despesas de uma empresa rural. Dessa forma, a busca por eficiência produtiva de bovinos leiteiros e de corte, ovinos e caprinos, deve ser uma das premissas para garantir a permanência do produtor nas atividades pecuárias, que atualmente apresentam margens de retorno econômico cada vez mais restrito.

Apesar da influência do componente genético sobre os fatores produtivos, a alimentação animal ainda é um entrave que compromete a produção, acentuando-se na região Nordeste, que apresenta sazonalidade de oferta de alimentos para ruminantes, devido às limitações climáticas. Além desse fator, há competição por determinados ingredientes para alimentação, como milho e soja, que são utilizados tanto na nutrição de ruminantes, como na de monogástricos e humanos, além da relação preço do grão/preço dos produtos de origem animal, que na maioria das vezes é desvantajosa, dificultando os aspectos produtivos (EMBRAPA, 2005).

Uma alternativa para superar problemas decorrentes dos fatores mencionados é a substituição de ingredientes clássicos utilizados na nutrição de ruminantes por alimentos alternativos capazes de suprir os rebanhos não apenas nos períodos de escassez de alimentos, mas também nos de maior disponibilidade, além de reduzir custos de produção na maioria dos casos. Como critérios para utilização de fontes alimentares alternativas devem ser considerados: custos dos alimentos supridos; custos com transporte, custos com estocagem e perdas, possíveis variações no conteúdo de nutrientes devido a diferentes procedimentos de processamento, possibilidade de toxidade, efeito sobre a digestibilidade e utilização da ração total, custos no fornecimento aos animais e efeito sobre o desempenho animal (SILVA et al., 2003).

Atualmente tem-se utilizado leguminosas arbóreas em consorcio com pastos de gramíneas, a fim de aumentar o valor nutritivo dos pastos e aumentar sua produção ao longo do tempo. Além da sustentabilidade, a 
GARCEZ, B.S. et al. Determinação dos parâmetros fermentativos de leguminosas pela técnica in vitro semi-automática de produção de gases. PUBVET, Londrina, V. 8, N. 5, Ed. 254, Art. 1683, Março, 2014.

inclusão ou manutenção de forrageiras arbóreas em pastagens elevam a disponibilidade de proteína bruta para ruminantes em regime de pasto, principalmente se as lenhosas forem leguminosas (MEDRADO et al., 1993).

A introdução de leguminosa na pastagem promove incrementos na produção animal, pelo aumento da qualidade e da quantidade da forragem em oferta, resultante não só da participação da leguminosa na dieta do animal, mas também dos efeitos indiretos relacionados com a fixação biológica de nitrogênio e seu repasse ao ecossistema de pastagem (PEREIRA et al., 2001).

Diante desta realidade, tem-se buscado opções para a alimentação animal no período critico inclusive o uso de vagens de leguminosas arbóreas, que apresentam produção no período seco. No Piauí, algumas espécies são utilizadas com esse objetivo, destacando-se o bordão-de-velho (Samanea saman (Jack.) Merr.) e o angico-branco (Anadenanthera colubrina (Vell.) Brenan) que têm sido estudados e revelaram ser alimentos com potencial para utilização na alimentação animal (MACHADO et al., 1999).

Objetivou-se com esse trabalho avaliar a composição bromatológica e a dinâmica de fermentação ruminal dos carboidratos totais (CT) de vagens de bordão-de-velho e angico-branco pela técnica in vitro semi-automática de produção de gases.

\section{MATERIAL E MÉTODOS}

O experimento foi realizado no Laboratório de Nutrição Animal (LANA) do Departamento de Zootecnia do Centro de Ciências Agrárias da Universidade Federal do Piauí, em Teresina - PI. Utilizaram-se amostras de vagens de bordão-de-velho (Samanea saman Jack.) e angico branco (Anadenanthera colubrina (Vell.) Brenan), pré-secas em estufa de circulação forçada de ar a $55^{\circ} \mathrm{C}$ durante $72 \mathrm{~h}$.

As vagens de bordão-de-velho foram coletadas durante o mês de setembro, no município de Teresina, PI, na Universidade Federal do Piauí (Centro de Ciências Agrárias). A região de Teresina apresenta um clima de 
GARCEZ, B.S. et al. Determinação dos parâmetros fermentativos de leguminosas pela técnica in vitro semi-automática de produção de gases. PUBVET, Londrina, V. 8, N. 5, Ed. 254, Art. 1683, Março, 2014.

transição sub-úmido, com dois períodos, um chuvoso e outro seco. A média pluviométrica é de $1360 \mathrm{~mm}$ anuais, distribuídos irregularmente, concentrando-se $70 \%$ nos meses de janeiro a abril (GOMES et al, 2005). A colheita foi feita manualmente, sendo coletadas vagens do solo e vagens ainda na árvore. O angico-branco foi coletado no município de Campo Maior (PI), no período de agosto de 2007, sendo feita coleta manual coletando-se folhas e ramas. A região apresenta clima quente com média anual de temperatura de $30^{\circ} \mathrm{C}$.

A composição químico-bromatológica foi obtida segundo as metodologias descritas por Silva \& Queiroz (2002), sendo determinados os teores de matéria seca (MS), proteína bruta (PB), fibra em detergente neutro $(F D N)$, fibra em detergente ácido (FDA), extrato etéreo (EE) e matéria mineral (MM).

O teor de carboidratos totais (CHOT) foi obtido a partir da equação proposta por Sniffen et al. (1992):

$$
\text { CHOT }(\%)=100-(\% \mathrm{~PB}+\% \mathrm{EE}+\% \text { Cinza })
$$

O conteúdo de carboidratos não fibrosos (CNF) foi calculado segundo Hall (2000), correspondente à diferença entre CHOT e FDN corrigida para proteína:

CNF $(\%)=100-[\% P B+(\% F D N-\% P B$ na FDN $)+\% E E+\%$ Cinza $]$

Para avaliação da produção de gases foi utilizada a técnica in vitro semi-automática de produção de gases, de acordo com Mauricio et al. (1999). Incubaram-se amostras de vagens de bordão-de-velho e angico branco com inóculo ruminal. $O$ inóculo foi coletado de um bovino adulto fistulado no rúmen, às 6 horas, antes do fornecimento da primeira refeição. As alíquotas das frações sólidas e líquidas do conteúdo ruminal foram coletadas diretamente do rúmen e acondicionadas em garrafas térmicas previamente aquecidas a $39^{\circ} \mathrm{C}$.

O animal foi alimentado com dieta à base de concentrado e volumoso, sendo o concentrado a base de milho e farelo de soja, e o volumoso a base de feno de tifton 85 . O concentrado era fornecido na quantidade de 7 
GARCEZ, B.S. et al. Determinação dos parâmetros fermentativos de leguminosas pela técnica in vitro semi-automática de produção de gases. PUBVET, Londrina, V. 8, N. 5, Ed. 254, Art. 1683, Março, 2014.

quilogramas por dias, sendo divido em duas refeições de pesos iguais, uma na parte da manhã (8:00) e outra na parte da tarde (16:00). O volumoso e o sal mineral eram fornecidos a vontade.

O inoculo ruminal foi submetido a homogeneização em liquidificado com frações sólida e líquida em igual proporção. Na filtragem utilizaram-se quatro camadas de tecido de algodão, em seguida o inóculo permaneceu a $39^{\circ} \mathrm{C}$, sob continua gaseificação $\mathrm{com} \mathrm{CO}_{2}$ para manutenção da anaerobiose até o momento da incubação.

As amostras foram incubadas utilizando-se frascos de vidro com capacidade para $160 \mathrm{~mL}$. Foram adicionados $1 \mathrm{~g}$ de amostra, $90 \mathrm{~mL}$ do meio de cultura, preparado segundo metodologia descrita por Mauricio et al. (1999), e $10 \mathrm{~mL}$ do inóculo ruminal. $\mathrm{O}$ meio foi gaseificado com $\mathrm{CO}_{2}$, os frascos foram vedados com rolhas de borracha e anilhas de alumínio e acondicionados em estufa de circulação forçada de ar a $39^{\circ} \mathrm{C}$ durante as leituras de pressão prédeterminadas. Frascos contendo somente meio de cultura e inóculo foram utilizados como controle.

As leituras de pressão foram realizadas $3,5,7,9,12,16,20,24,28$, 34, 46, 59 e 72 após o início da incubação, com o auxílio de um transdutor de pressão conectado a uma válvula de três saídas, segundo Mauricio et al. (1999).

A dinâmica de fermentação ruminal foi estimada pelo modelo de Gompertz: $\quad V_{T}=V_{F} \times \exp (-C \times \exp (-A \times t))$. Os parâmetros estimados foram comparados segundo um delineamento inteiramente casualizados com três tratamentos e cinco repetições utilizando-se o Generalized Linear Model Procedures (PROC GLM) do SAS (2000) e as médias dos tratamentos e suas respectivas interações pelo teste de Student-Newman-Keuls (SNK), através do procedimento PROC GLM do SAS (2000). 
GARCEZ, B.S. et al. Determinação dos parâmetros fermentativos de leguminosas pela técnica in vitro semi-automática de produção de gases. PUBVET, Londrina, V. 8, N. 5, Ed. 254, Art. 1683, Março, 2014.

\section{RESULTADOS E DISCUSSÃO}

A composição bromatológica do bordão-de-velho e do angico-branco, encontra-se na tabela 1 . O teor de MS para as vagens de bordão de velho $(86,63 \%)$ foi levemente superior aos $85,5 \%$ encontrado por Duke et al. (1983), para vagens de plantas da América Central e aos $83 \%$ encontrado por Moreira Filho et al. (2008) que trabalhou com inclusão de vagens dessa leguminosa em silagens de capim elefante, sendo inferior aos $94,5 \%$ obtidos por Machado et al. (2005).

Tabela 1. Composição bromatológica (\% na matéria seca) de vagens de bordão-de-velho (Samanea saman Jack.) e angico branco (Anadenanthera colubrina (Vell.))

\begin{tabular}{|c|c|c|c|c|c|c|c|c|}
\hline \multirow{2}{*}{ Vagens } & MS* & PB & CHOT & FDN & FDA & $\mathrm{EE}$ & MM & \multirow[t]{2}{*}{ CNF } \\
\hline & $(\%)$ & \multicolumn{6}{|c|}{$(\% M S)$} & \\
\hline $\begin{array}{l}\text { Bordão-de- } \\
\quad \text { velho }\end{array}$ & 86,63 & 16,54 & 78,71 & 25,56 & 22,37 & 0,74 & 4,01 & 54,45 \\
\hline $\begin{array}{l}\text { Angico- } \\
\text { Branco }\end{array}$ & 88,87 & 20,67 & 72,33 & 60,85 & 42,16 & 1,95 & 5,10 & 24,93 \\
\hline
\end{tabular}

*MS: matéria seca; PB: proteína bruta; CHOT: carboidratos totais; FDN: fibra em detergente neutro; FDA: fibra em detergente ácido; EE: extrato etéreo; MM: matéria mineral; CNF: carboidratos não fibrosos

Para o angico, o teor de MS $(88,87 \%)$ foi superior aos $87,55 \%$ encontrado por Azevedo et al. (1987). As amostras apresentaram um elevado teor de matéria seca, possivelmente, devido a tratar-se de um material bastante maduro, onde a perda de umidade ainda na planta foi 
GARCEZ, B.S. et al. Determinação dos parâmetros fermentativos de leguminosas pela técnica in vitro semi-automática de produção de gases. PUBVET, Londrina, V. 8, N. 5, Ed. 254, Art. 1683, Março, 2014.

complementada pela perda após cair no solo devido a uma secagem natural provocada pelas elevadas temperaturas no período (MACHADO et al., 2005).

O teor de PB na MS no bordão de velho (16,54\%) foi superior aos $14,85 \%$ e $13,3 \%$ relatados respectivamente por Machado et al. (2005) e Nascimento et al. (1996), sendo inferior aos $17,11 \%$ encontrado por Cavalcante et al. (2004). O teor de PB do angico (20,67\%) foi inferior aos 23,9\% encontrado por Nascimento et al. (1996) e superior ao relatado por Passos et al. (1990), que encontrou valores médios de 14,52\%. Os percentuais de PB estão acima do intervalo de $6 \%$ a $8 \%$ de PB recomendado por Van Soest (1994) para uma efetiva fermentação microbiana ruminal.

Em relação ao $\mathrm{EE}$, o teor de 0,74 encontrado para o bordão-de-velho encontrou-se superior aos 0,59\% encontrado por Moreira Filho et al. (2008) e significativamente inferior aos $12,16 \%$ encontrado em vagens secas por Nascimento et al. (1996). Para o angico o teor obtido $(1,9 \%)$ foi superior ao mencionado por Passos et al. (1990) que foi de 1,69\%, porem inferior aos $2,78 \%$ e $8,8 \%$ obtidos por Nascimento et. al. (1996) e Costa et al. (1973) respectivamente. Os níveis de lipídeos nas forrageiras tropicais são muito reduzidos, onde os galactolipídeos constituem cerca de $60 \%$ dessa fração, principalmente ácidos linolênico (60 a 70\%) linoléico e palmítico (JARBAS JUNIOR et al., 2007). Esses baixos valores de lipídeos tornam-se importantes na dieta de ruminantes, pois suplementações lipídicas altas, acima de 5\%, podem comprometer o consumo de matéria seca por esses animais (BERCHIELLI, 2006).

Os Teores encontrados para FDN e FDA das vagens de bordão-develho (25,56 e 22,37\%, respectivamente) não são considerados altos, o que sugere uma alta digestibilidade da matéria seca. Porém os teores de FDN, não são os únicos indicadores de uma boa digestibilidade, tais como teores de carboidratos solúveis e teores de nitrogênio, pois, além disso, deve-se considerar o teor de componentes indigestíveis como lignina e taninos condensados (BERCHIELLI, 2006). 
GARCEZ, B.S. et al. Determinação dos parâmetros fermentativos de leguminosas pela técnica in vitro semi-automática de produção de gases. PUBVET, Londrina, V. 8, N. 5, Ed. 254, Art. 1683, Março, 2014.

O baixo teor de FDA indica baixos níveis de componentes indigeríveis na parede celular, pois essa parte da fibra é constituída na sua quase totalidade por lignoceluose. A lignina é um polímero que envolve a fibra e a proteína, tornando-as inacessíveis à digestão enzimática. Segundo Berchielli (2006), em leguminosas, o conteúdo de lignina é confinado somente no xilema e não se dissemina através de diferentes tipos de tecidos, isso mostra que em tecidos lignificados de leguminosas a concentração de lignina por unidade de parede celular será muito maior e parece impedir completamente a digestão da parede secundária.

Para o angico, os teores de FDN e FDA (60,85 e 42,16\%), mostraram-se altos, em comparação aos $36,36 \%$ e $26,76 \%$ para FDN e FDA, respectivamente, obtidos por Passos et al. (1990). Os teores de FDA apresentaram-se bastante significativos podendo ter sido afetados principalmente pelas condições climáticas do período de coleta, pois segundo Van Soest (1994), elevadas temperaturas, promovem rápida lignificação da parede celular, acelerando a atividade metabólica da célula, promovendo a rápida conversão de produtos fotossintéticos em componentes dessa parede.

Os teores de MM para o bordão-de-velho tiveram uma média de $4,01 \%$, apresentando variação significativa dentre as amostras $(3,74 \%$ a $4,63 \%)$, esses valores mostraram-se superiores aos $2,82 \%$ e $2,1 \%$ obtidos por Nascimento et al. (1996) e Duke et al. (1983) respectivamente, e semelhante ao encontrado por Cavalcante et al. (2004). Segundo Silva e Queiroz (2002), a composição mineral de algumas vagens, está condicionada principalmente a concentração de sílica no solo, que aumenta o teor de cinzas, de acordo com o tempo que essa vagem fique em contato com o mesmo. Em relação ao angico, o teor obtido $(5,10 \%)$ foi superior aos $4,10 \%$ encontrado por Azevedo et al. (1987) e inferior ao encontrado por Costa (1973), que foi de 5,89\%, trabalhando com ramas dessa leguminosa.

O teor de carboidratos totais das vagens de bordão de velho $(78,71 \%)$ foi superior aos $55.3 \%$ encontrado por Duke (1983), mostrando assim melhor teor energético das vagens de nossa região. Já para o angico, o 
GARCEZ, B.S. et al. Determinação dos parâmetros fermentativos de leguminosas pela técnica in vitro semi-automática de produção de gases. PUBVET, Londrina, V. 8, N. 5, Ed. 254, Art. 1683, Março, 2014.

teor de carboidratos $(72,23 \%)$ foi bastante superior ao encontrado por Costa (1973), que foi de $34,85 \%$ onde se analisou apenas as ramas dessa leguminosa.

As estimativas dos parâmetros de produção de gases dos CT encontram-se na Tabela 2. Verificou-se diferença entre as forrageiras para o potencial máximo de produção de gases (Vf). Os maiores volumes de gases foram verificados no bordão-de-velho, enquanto que a menor capacidade de fermentação foi observada no angico-branco que produziu os menores volumes de gases, possivelmente devido ao maior teor de FDA.

Tabela 2. Parâmetros cinéticos de fermentação ruminal do angico branco e do bordão-de-velho estimados pelo modelo Gompertz

\begin{tabular}{lcc}
\hline \multirow{2}{*}{ Parâmetros $^{1}$} & \multicolumn{2}{c}{ Alimentos } \\
\cline { 2 - 3 } $\mathrm{Vf}\left(\mathrm{mL} \cdot \mathrm{g}^{-1} \mathrm{MS}\right)$ & angico-branco & bordão-de-velho \\
$\mathrm{C}\left(\mathrm{h}^{-1 / 2}\right)$ & $127,32 \mathrm{~b}$ & $342,26 \mathrm{a}$ \\
$\mathrm{A}$ & $0,07 \mathrm{~b}$ & $0,08 \mathrm{a}$ \\
& $1,88 \mathrm{~b}$ & $1,90 \mathrm{~b}$
\end{tabular}

1 Vf: potencial máximo de produção de gases; c: taxa constante de produção de gases do material potencialmente degradável; $A$ : fator constante de eficiência microbiana.

Fato esse confirmado por Mauricio et al. (2003), que ao utilizar a técnica de produção de gases para avaliar o potencial de fermentação de silagens de sorgo, observou correlação negativa entre a taxa de produção e o potencial máximo de produção de gases $(P<0,01)$ e os teores de FDA e de lignina, indicando interferência dessas frações sobre a fermentabilidade da amostra.

Esse maior potencial também pode estar associado aos maiores teores de substratos prontamente fermentáveis no bordão-de-velho, evidenciando, dessa forma, a superioridade no valor do potencial máximo de 
GARCEZ, B.S. et al. Determinação dos parâmetros fermentativos de leguminosas pela técnica in vitro semi-automática de produção de gases. PUBVET, Londrina, V. 8, N. 5, Ed. 254, Art. 1683, Março, 2014.

produção de gases (Vf) (MAURICIO et al., 2003). Segundo Noguera et al. (2004) os processos de adesão e colonização do substrato pelos microrganismos são facilitados quando há disponibilidade de substrato de rápida fermentação. Para Tomich et al. (2003), além da disponibilidade de substrato prontamente fermentáveis, as características físicas e químicas da parede celular da amostra também são capazes de facilitar a colonização microbiana. Preconizando-se que a retenção média do alimento no rúmen seja de $48 \mathrm{~h}$, seria desejável que a maior parte dos nutrientes digestíveis fosse fermentada dentro deste intervalo.

A menor taxa de produção de gases do angico pode ser explicada também devido ao seu alto teor de proteína, segundo Khazaal et al. (1995), a incubação de substratos ricos em proteína resultar na formação de bicarbonato de amônio, a partir de $\mathrm{CO}_{2}$ e amônia, reduzindo, assim, a contribuição de $\mathrm{CO}_{2}$ para a produção total de gás.

A curva de produção cumulativa de gases do bordão-de-velho e do angico branco é demonstrada na figura 1 . Nota-se, graficamente, a superioridade do bordão de velho principalmente nos tempos iniciais de fermentação, esse fato pode ser devido ao maior teor de carboidratos não fibrosos da vagem em relação ao angico, fazendo com que ocorra maior colonização e maior produção de gases.

A energia utilizada pelos microrganismos nas primeiras horas de incubação é proveniente, quase que totalmente, da fermentação dos carboidratos não-fibrosos (Azevêdo et al., 2003), o que condiz com a maior velocidade de produção de gases nos tempos iniciais, isso explica a alta taxa de produção de gases no inicio da fermentação, pois o bordão-de-velho apresentou maiores valores de carboidratos não fibrosos $(54,45 \%)$ em relação ao angico $(24,93 \%)$. 
GARCEZ, B.S. et al. Determinação dos parâmetros fermentativos de leguminosas pela técnica in vitro semi-automática de produção de gases. PUBVET, Londrina, V. 8, N. 5, Ed. 254, Art. 1683, Março, 2014.

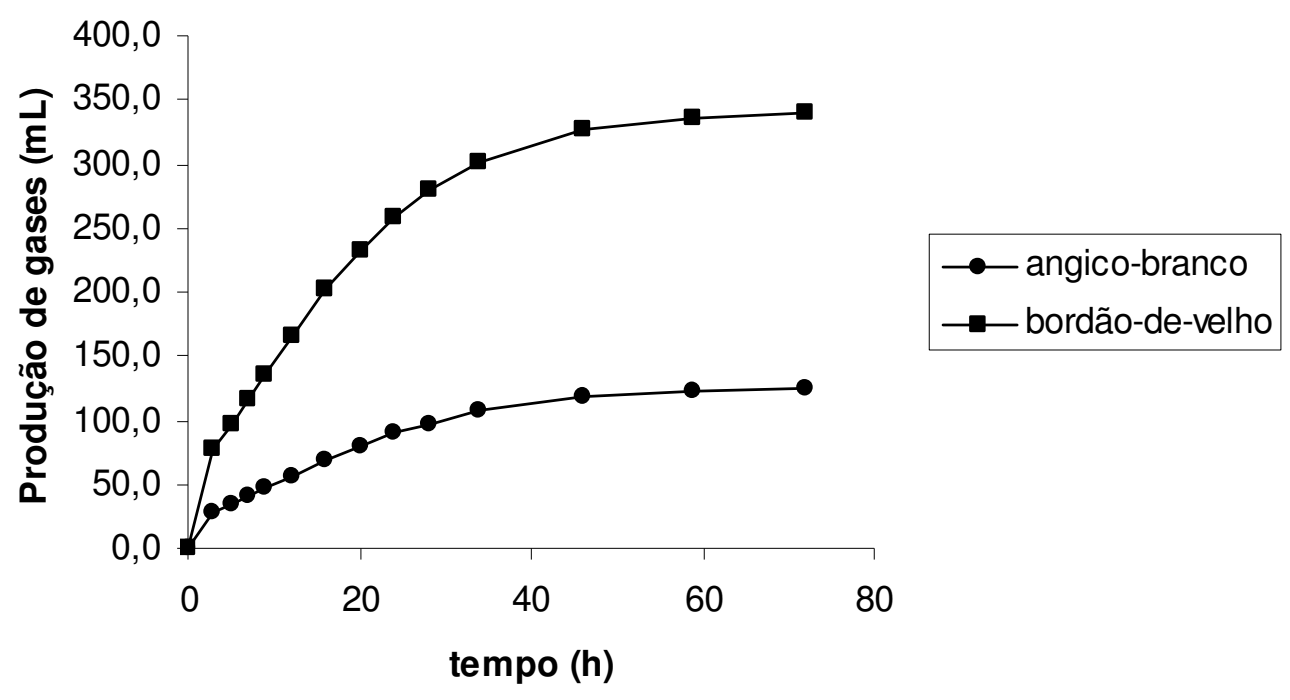

Figura 1. Curvas de produção cumulativa de gases dos CT do bordãode-velho e do angico branco

Segundo Beuvink \& Spoelstra (1992), a relação propionato/acetato pode interferir no volume de gases produzidos, onde a maior produção de acetato favorece a produção de gases. Existe uma interação entre os ácidos graxos voláteis e o meio de cultura (tampão), em que o decréscimo no pH favorece a produção de propionato e, consequentemente, redução na produção de gases. A formação do propionato é a única via que envolve a captura do hidrogênio ( $\mathrm{H} 2)$ e não envolve a formação de dióxido de carbono (CO2) não contribuir para a formação dos gases (Van Soest, 1994).

As maiores taxas de produção de gases foram obtidas, para as duas leguminosas, aproximadamente após oito horas de fermentação, fato provavelmente devido à fermentação dos carboidratos não fibrosos. Nogueira et al. (2006), comparando substratos com diferentes teores de carboidratos solúveis obtiveram maior degradação para aqueles que apresentaram menor produção de gases. 
GARCEZ, B.S. et al. Determinação dos parâmetros fermentativos de leguminosas pela técnica in vitro semi-automática de produção de gases. PUBVET, Londrina, V. 8, N. 5, Ed. 254, Art. 1683, Março, 2014.

\section{CONCLUSÕES}

O bordão-de-velho e o angico-branco apresentaram potencial para uso na alimentação de ruminantes por serem de boa qualidade do ponto de vista fermentativo.

O bordão de velho apresenta melhores parâmetros fermentativos, o que pode ser atribuído ao maior teor de carboidratos não fibrosos, em comparação com o angico branco.

\section{REFERÊNCIAS BIBLIOGRÁFICAS}

AZEVEDO, G. Pastos Arbóreos, 2a ed. Mossoró, UFV, 1987, 32p.

BERCHIELLI, T. T. Nutrição de Ruminantes. Jaboticabal: Funep. São Paulo. 2006. 583p.

BEUVINK, J.M.W.; SPOELSTRA, S.F. Interactions between substrate, fermentation endproducts, buffering systems and gas production upon fermentation of different carbohydrates by mixed rumen microorganisms in vitro. Applied Microbiology and Biotechnology, v.37, n.15, p.505-509, 1992.

CAVALCANTE, P. V. T. H. et al Potencial forrageiro do bordão de velho para uso em sistemas silvipastoris, in: IX encontro de iniciação cientifica da UEMA, 2004, São Luis. Anais... São Luis: IX encontro de iniciação cientifica da UEMA, [2004] (CD-ROM).

COSTA, B. M. Forrageiras Arbóreas e suculentas para formação de pastagens, Cruz das almas, BA: ITAL, 1973, 24p. (Circular tecnica, 34).

DUKE. J. A. Handbook of energy crops. West Lafayette: Purdue University, 1983.

GOMES, A.N. et al. Evapotranspiração de referência mensal para o estado do Piauí. Revista Brasileira de Engenharia Agrícola e Ambiental, v.9, n.4, p.560-564, 2005.

HALL, M.B. Neutral detergent-soluble carbohydrates. Nutritional relevance and analysis. Gainesville: University of Florida, 2000. 76p.

JARBARS JUNIOR, P. Fatores que afetam os valores nutritivos de forrageiras tropicais. 2007. 67p. Tese (Mestrado) - Universidade Castelo Branco, Rio de Janeiro.

MACHADO, A. M. Avaliação da produção de litera e de vagens de três leguminosas arbororéas nativas do nordeste. 2005. 75p. Tese (Mestrado) - Universidade Federal Rural de Pernambuco - Recife.

MACHADO, F.A. et al. et al. Valor nutritivo da vagem de faveira (Parkia platycephala Benth.) para ruminantes. Revista Cientifica de Produção Animal. v.1, n.1, p. 39-43, 1999.

MAURICIO, R. M. et al. A semi-automated in vitro gas production technique for ruminant feedstuff evaluation. Animal Feed Science and Technology, v. 79, n.23, p.321-330, 1999.

MAURÍCIO, R. M. et al. Relação entre pressão e volume para implantação da técnica in vitro semi-automática de produção de gases na avaliação de forrageiras tropicais. Arquivo

Brasileiro de Medicina Veterinária e Zootecnia. Belo Horizonte, vol.55, n.2, p.216-219, 2003. 
MAURÍCIO, R. M. et al. Uso de líquido do rúmen e fezes como fonte de inoculo para a técnica in vitro de produção de gás. In: REUNIÃO ANUAL DA SOCIEDADE BRASILEIRA DE ZOOTECNIA, 1998. Botucatu. Anais... Botucatu: SBZ, 1998.

MAURICIO, R.M. et al. Comparison of bovine rumen liquor and bovine faeces as inoculum for an in vitro gas production technique for evaluating forages. Animal Feed Science and Technology, v.89, n.46, p.33-48, 2001.

MEDRADO, M.J.S. Estabelecimento de leguminosas arbustivas arbóreas forrageiras. In: SIMPOSIO SOBRE USOS MULTIPLOS DE LEGUMINOSAS ARBÓREAS E ARBUSTIVAS, 1., Nova Odessa, SP, 1993. Anais... Nova Odessa, SP, Instituto de Zootecnia, 1993. p. 63-94.

MOREIRA FILHO, M. A. et.al. Composição e fermentação da silagem de capim-elefante com adição de vagens de bordão-de-velho, in: Associação Brasileira de Zootecnistas, 2008, João Pessoa. Anais... João Pessoa: Associação Brasileira de Zootecnistas, [2008] (CDROM).

NASCIMENTO, M. P. S. C. B. et al. Forrageiras da bacia do Parnaíba: usos e composição química. Teresina: EMBRAPA/CPAMN/Recife: associação Plantas do Nordeste, 1996. 86 p.

NOGUEIRA, U.T. Comparação de substratos com diferentes quantidades de carboidratos solúveis utilizando a técnica in vitro semi-automática de produção de gases. Arquivo Brasileiro de Medicina Veterinária e Zootecnia, v.58, n.4, p.633-641, 2006.

PASSOS, R. A. M. Avaliação bromatológica e do valor nutritivo de forrageiras nativas do nordeste. 1990. 87p. Tese (Mestrado). - Universidade Federla de Pelotas, Rio Grande do Sul.

PEREIRA, J.M., J.R. Santana e C.P. Rezende. 1996. Pastagem formada por capim-humidicola (brachiarias alternativas para aumentar o porte de nitrogênio em $B$. humidicola (Rendle) Schweickt). In: Reunião da Sociedade Brasileira de Zootecnia, 33. Anais da Reunião da Sociedade Brasileira de Zootecnia. SBZ. Fortaleza. p. 38-40.

SANTOS, R. A. et al. Estimativa da degradabilidade ruminal de alimentos utilizando a técnica de produção de gás em bovinos, ovinos e caprinos. Ciência e Agrotecnologia. Lavras, v.27, n.3, p. 689-695, 2003.

SAS INSTITUTE (SAS). Statistical Analysis Systems User's Guide. Version 8, Cary, NC: SAS Institute, 2000.

SILVA, D.J.; QUEIROZ, A.C. Análise de Alimentos: métodos químicos e biológicos. 3.ed., Viçosa: UFV, 2002.

SILVA, K. T. et al. Utilização de fezes (eqüina ou bovina) em substituição ao líquido ruminal como fonte de inóculo para determinação da digestibilidade in vitro de alimentos para ruminantes. Acta Scientiarum Animal Sciences. Maringá, v.25, n.2, p.355-361, 2003.

SNIFFEN, C.J. et al. A net carbohydrate and protein system for evaluating cattle diets: II. Carbohydrate and protein availability. Journal of Animal Science, v.70, n.11, p.3562-3577, 1992.

THEODOROU, M. K. et al. A simple gas production method using a pressure transducer to determine the fermentation kinetics of ruminant feeds. Animal Feed Science and Technology, v. 48, n.14, p.185-197, 1994.

TOMICH, T. R. et al. Composição bromatológica e cinética de fermentação ruminal de híbridos de sorgo com capim-sudão. Arquivo Brasileiro de Medicina Veterinária e Zootecnia, vol.55, n.6, p.747-755, 2003.

VAN SOEST, P.J. Nutritional ecology of the ruminant. 2.ed. Cornell: Cornell University, 1994. 476p. 